A three-minute test of implicit language processing for large sample sizes: Proof-of-concept application in a public science event

Brekelmans, G. ${ }^{1,2}$, Bruns, C. ${ }^{1}$, Meitanis, V. $^{1}$, Coleman, M. D. ${ }^{1}$, \& Zimmerer, V. C. ${ }^{1}$

${ }^{1}$ Department of Language and Cognition, University College London, United Kingdom

${ }^{2}$ Department of Biological and Experimental Psychology, Queen Mary University of London, United Kingdom

[THIS PREPRINT IS CURRENTLY UNDER REVIEW]

Corresponding author:

Vitor Zimmerer

Chandler House

2 Wakefield Street

London WC1N 1PF

United Kingdom

v.zimmerer@ucl.ac.uk

\title{
Declarations
}

The authors have no relevant financial or non-financial interests to disclose, no conflicts of interest to declare that are relevant to the content of this article. All authors certify that they have no affiliations with or involvement in any organization or entity with any financial interest or non-financial interest in the subject matter or materials discussed in this manuscript. The authors have no financial or proprietary interests in any material discussed in this article. 


\section{A three-minute test of implicit language processing for large sample sizes: Proof-of-concept application in a public science event}

\section{Abstract:}

Research into human language processing is made challenging by the implicit nature of processes, the short time-window in which they take place, and heterogeneity within the population. We used a word monitoring task to measure implicit sensitivity to grammar, semantics, and the strength of word collocations, when listening to natural spoken sentences. We report substantial and novel adjustments to the paradigm, which allowed a participant to be tested in about three minutes, and data from a proof-of-concept study for which we recruited 125 visitors of different backgrounds to a science event. Linear mixed-effects models suggest that participants' response time to target words was slower when words were less predictable in their grammatical, semantic, or collocational context, with no significant difference between trial conditions. However, in non-native speakers, grammatical manipulation was numerically less effective than manipulations of semantics and word collocations, and the effect was close to the significance boundary.. There was no significant effect of age on language sensitivity. Findings either replicated previous studies using standard word monitoring methods, or were compatible with theories on language processing, suggesting that the novel adjustments can be applied in situations where participants' time is limited, e.g. at events, in schools or online.

Keywords: Psycholinguistics; Implicit processing; Word monitoring; Public event 


\section{Introduction}

\section{1 "Predicting language"}

The London Bloomsbury Festival is a yearly arts, literature, performance and science event celebrating the district's "pioneering diversity". University College London (UCL) is located in that area and a regular contributor. 2016's festival had "Language" as its theme and we contributed with a public science installation with the aim of engaging the public, raising awareness to language as a cognitive process, and testing sensitivity to different aspects of linguistic information in a larger public sample which is more heterogeneous than is common in psychological studies. To accomplish this, we made substantial modifications to an established empirical paradigm, shortening the protocol from typically half an hour or longer for each participant to three minutes in order to lower the barrier to participation.

Language processing is a subject critical to a range of disciplines. It informs linguistic theory, but also applies to branches such as education and clinical science, for example to track early development or profile and detect neurological disorders. However, research on language processing faces three basic challenges: First of all, much of language processing happens implicitly; speakers have no intuitive insight to the processes that underlie lexical or grammatical interpretation (Ellis, 2008), meaning that measures of implicit processing may be more informative than explicit data such as from questionnaires or grammaticality judgments. Second, processing happens within fractions of a second: Event-related EEG potentials show that many language-related effects, such as of the acceptability of a word within its context, or of effort in syntactic processing, take place at around half a second after onset of the critical stimulus (Kutas, van Petten, \& Kluender, 2006), which should be regarded as a call for more sensitive measures of linguistic performance. Third, there are considerable 
individual differences within populations (which have long been underestimated), meaning that experimental data from homogeneous groups, such as university students, should be generalized only with caution (Kidd, Donnelly, \& Christiansen, 2018; Street \& Dąbrowska, 2010, 2014).

The Bloomsbury Festival was an opportunity for us to carry out a study that addresses these three issues, and at the same time offer an engaging experience which encourages participants to think about the cognitive processes underlying language use. The design of the installation was based on the idea that listeners implicitly form predictions about incoming information based on what they hear at a given moment (Clark, 2013; Ferreira \& Chantavarin, 2018). These predictions determine anticipatory activation, and linguistic stimuli which correspond to these predictions are easier to process, while stimuli that violate predictions require greater effort. We focused on three levels of language processing: (1) Grammatical processing, which we use to make predictions about incoming structure and word types; e.g., the word combination I want to makes the listener expect a verb or adverb. (2) Lexicalsemantic processing, which we use to make predictions about the possible meaning of the next words; e.g., For dinner I would like makes the listener expect a reference to food or drinks. (3) Processing of collocation patterns in language, which helps us make predictions about specific words; e.g., the words salt and can lead to the pre-activation of pepper (Conklin \& Schmitt, 2012; Siyanova-Chanturia, Conklin, Caffarra, Kaan, \& van Heuven, 2017). Fittingly, we named our installation "Predicting Language", a title which can be interpreted in two ways: Individuals predicting language input while listening, and the language system itself being predictive in nature. 
The public event allowed us to investigate effects of age, gender and native language (English as native (L1) or non-native (L2) language) on sensitivity to the three features of language described above, namely (1) grammatical structure, (2) lexical-semantic information, and (3) word collocations. We were interested in whether results from the new WMT task were consistent with previous observations as well as language processing theories, in order to validate the methods. We also observed participants' reactions to the event as an indicator of engagement.

\subsection{The Word Monitoring Task (WMT)}

We designed a word monitoring task (WMT; Kilborn \& Moss, 1996; Marslen-Wilson \& Tyler, $1975,1980)$, a response time measure of implicit spoken language processing. The paradigm tests how recognition of a single word is affected by word context. In a typical WMT, a target word (e.g. city) is presented to the participant. Then, a sentence is presented which contains the target word, and the participant has to press a response button as quickly as possible when they recognize the word in the sentence. Response time (RT) is measured. Test conditions typically differ in whether the target word occurs in a context that makes it predictable, e.g. You can reach the city in little time, or less predictable, e.g. You can arrive the city in little time. In this example, city appears in a grammatical context in first condition (the verb reach takes a direct object) and in an ungrammatical context in the second condition (the verb arrive does not). Typically, increase in processing effort results in a RT increase, such as when the target word is presented in a position that makes it less predictable or a violation. Sensitivity to linguistic information in processing is measured by subtracting the RT from the less predictable condition from the RT of the predictable condition. According to the definition of "implicit processing" offered by Shanks (2005), WMT is a measure of implicit 
processing because participants following the instructions are not aware of the critical processes while they take place. By focusing on pressing the button as soon as the target word appears, they are engaged in something other than reflecting on the properties of the stimulus sentences. Suzuki and DeKeyser (2015) found that language sensitivity measured in a WMT correlated with performance in a serial reaction task, an implicit measure of nonverbal sequence learning.

Sensitivity varies depending on the cognitive system of the individual. There are striking deviations in clinical cases, such as developmental language disorder, aphasia (a language impairment caused by brain injury or degeneration) or schizophrenic thought disorder (Baum, 1989; Haarmann \& Kolk, 1994; Kuperberg, McGuire, \& David, 1998; Montgomery \& Leonard, 2006). However, the WMT is also used to investigate language processing in second language speakers (Granena, 2013; Kilborn, 1992; Suzuki, 2017; Suzuki \& DeKeyser, 2015) and aging (Tyler et al., 2010; Waldstein \& Baum, 1992).

In order to motivate participants to engage with the experiment, we told them that they would see their average RT at the end of the task. After the task, we gave each participant a button with a logo and the phrase "Language Predictor", and offered to write their average RT on it. We expected participants to be motivated and respond as quickly as possible, and to compare the average RT with friends. To further increase engagement, the installation had an animated PowerPoint presentation about predictive language processing, included one offline activity involving predicting words (a variation of the cloze task), and displayed the cumulative results from one of the test computers on a screen (see Methods section). Researchers were present to discuss language processing with visitors. 


\subsection{Methodological innovations}

One major hurdle in applying the WMT in a public science event is the duration of the task. The 'Predicting Language' installation would run for six hours on one day and we expected hundreds of visitors. We had two test computers available and were aware that participants would not want the activity to be longer than a few minutes. WMTs have always been designed for smaller subject groups, and contained dozens of trials: for example, MarslenWilson and Tyler (1975) had 81 sentences for each participant, Baum (1991) 150 sentences, Haarmann and Kolk (1994) 160 sentences, Kuperberg, McGuire and David (1998) had 76 sentences and Granena (2013) 120 sentences. For the current study, we decided to present 12 sentences to each participant.

In contrast to how WMTs are typically designed (see Marinis, 2010, for a review of methods), this restriction made a number of deviations necessary. It is normal for each target word to be presented to each participant in both predictable and less predictable conditions, e.g. city in grammatical and ungrammatical sentences. This enables a contrast of each item pair at a within-subject level, offering more robust data. To avoid participants becoming aware of the manipulation, trials with the same target word are spaced out across sessions or trial blocks. The brevity of our study made such a design impossible, and we therefore presented each target word only once to the participant. Half of the participant sample encountered it in the predictable, and half in the less predictable condition. As a result, the effect of the predictability manipulation was dependent on between-subject comparisons.

The other important deviation is the omission of filler and catch trials. Filler trials contain a target word but are not relevant to the hypotheses and are included to keep participants from becoming aware of the task manipulation. Catch trials contain no target word and therefore 
require no response. These can be included to raise participant alertness, and to avoid participants pressing the button purely mechanically, without listening to the linguistic content of the task. Our experiment, however, contained only hypothesis-relevant trials. Based on our experience designing and running WMT tasks, we expected that the brief duration of the experiment would keep participants from losing focus, and that this short duration in combination with presenting each target word once would limit participant awareness of the task manipulation. In making changes to the paradigm, we saw an opportunity to contribute methods which could be used not only in public events, but also in other settings where participants' time could be limited, such as schools or online, where we expect individuals will more likely participate and complete a task if it is short. For instance, Hartshorne, Tenenbaum and Pinker (2018), who recruited more than 650,000 participants for their vocabulary quiz, highlighted that in order to go viral, a test has to be entertaining, motivating and quick to complete.

The project had ethical approval from the UCL Department of Language and Cognition Ethics committee (ID: LCRD.2016.06). We had permission to include people younger than 18, but had no permission to use their data and therefore removed them before analysis.

\section{Methods}

\subsection{Installation}

We designed an interactive 'Predicting Language' installation as part of a one-day public event, on Saturday, November 22nd 2016, from 11am to 5pm in the UCL Main Quad Marquee. We shared the event space with other installations. Figure 1 shows the setup of the installation which included a scientific slideshow presentation about prediction in language, 
a sentence completion (cloze) task, and a WMT with real-time display of results. The sentence completion task was not set up as an experiment, but rather, as a way for visitors to further engage with the topic of the installation. We describe the task and the results in the Appendix. Moreover, each visitor could take a badge with a logo of our installation.

Figure 1

Design of the Predicting Language installation.

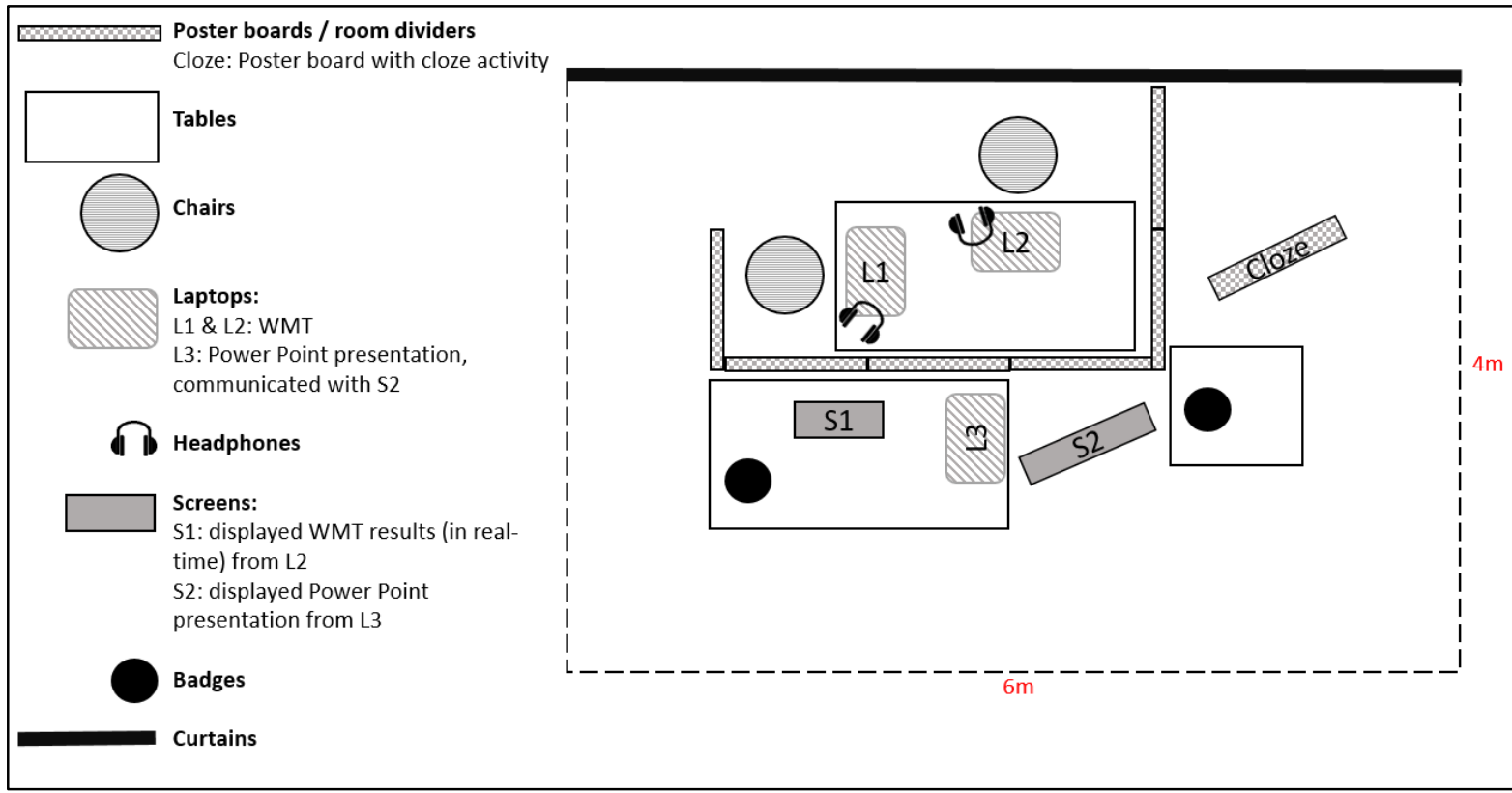

The event was widely publicized in London through press and social media. Organizers advertised the Predicting Language installation with "take part in cutting edge research" in the festival brochure (2016), and the program described it as: "Take part in a live experiment, with researchers from the Department of Language and Cognition". Visitors who stopped at the installation were approached by a researcher and asked if they were interested in taking 
part. Some participants had heard about the experiment already and approached us. They were given an information sheet, had time to ask questions about the study and, if they agreed to take part, gave written consent to storage and use of their anonymized data for research purposes. The experimenter would then wait for a test computer to become available and lead the participant to the machine.

\subsection{Participants}

We collected data from 136 volunteers between 7 and 79 years (mean $=39.8 ; S D=17.9$ ). For analysis, we only included participants who were 18 years or older since we did not have approval to analyze data from minors. Our final sample consisted of 125 volunteers between 18 and 79 years (mean $=42.2, S D=16.6$ ). Of these, 83 were native speakers of English; 74 were male, 50 were female and one participant was non-binary. No participant reported a history of language or hearing impairment, stroke or other brain damage.

\subsection{Materials}

The WMT consisted of 12 sentence pairs, divided into three experimental conditions: grammatical, lexical-semantic, and word collocations. We split stimuli into two lists of 12 sentences, with equal numbers of predictable and less predictable items from each condition. Table 1 presents the stimuli. Each condition comprised four sentence pairs. For each pair, there was one sentence where the appearance of the target was more likely given its context (i.e., semantically / syntactically correct sentence, common word collocation) and a counterpart sentence with violated semantic or syntactic context, or with a less common collocation. 
To measure RT to target words, it is essential to accurately determine the onset time of target words in the sound file. Target words beginning with plosives $(/ \mathrm{p} /, / \mathrm{t} /, / \mathrm{k} /, / \mathrm{b} /, / \mathrm{d} /, \mathrm{g} /$, affricates $/ \mathrm{t} f /, / \mathrm{d}_{3} /$ or fricatives $/ \mathrm{s} /, / \mathrm{z} /, / \mathrm{f} /, / \mathrm{v} /$ are easiest for determining word onset (Cruttenden, 2008; Brekelmans \& Meitanis, 2016). With the exception of one target word (icing), all began with a plosive, affricate or fricative. Each target word appeared at the same sentence position in both sentences of the pair.

Auditory stimuli were recorded by a female native speaker of Standard Southern British English in a sound-attenuated booth. We determined the onset points of target words in each sentence, using Praat (Boersma \& Weenink, 2019). This allowed us to determine monitoring latencies by subtracting a participant's RT by the onset point. 
Table 1

WMT stimulus conditions, targets, and sentences.

\begin{tabular}{|c|c|c|c|}
\hline Condition & Target & Sentential context & $\begin{array}{l}\text { Predictable / } \\
\text { less predictable }\end{array}$ \\
\hline \multirow{9}{*}{$\begin{array}{l}\text { Semantic } \\
\text { violations }\end{array}$} & \multirow{2}{*}{ crawl } & $\begin{array}{l}\text { I saw a spider that was very big, crawl under } \\
\text { my bed. }\end{array}$ & $\mathrm{P}$ \\
\hline & & $\begin{array}{l}\text { I saw a fish that was very big crawl under my } \\
\text { bed. }\end{array}$ & LP \\
\hline & \multirow{2}{*}{ cucumber } & $\begin{array}{l}\text { For my salad, I should buy some cucumber } \\
\text { from the market. }\end{array}$ & $\mathrm{P}$ \\
\hline & & $\begin{array}{l}\text { For my guitar, I should buy some cucumber } \\
\text { from the market. }\end{array}$ & LP \\
\hline & \multirow{2}{*}{ crowded } & $\begin{array}{l}\text { The room is very small and crowded in my } \\
\text { opinion. }\end{array}$ & $\mathrm{P}$ \\
\hline & & $\begin{array}{l}\text { The mouse is very small and crowded in my } \\
\text { opinion. }\end{array}$ & LP \\
\hline & \multirow{2}{*}{ tree } & $\begin{array}{l}\text { On Sunday, we will plant a small tree with } \\
\text { Alex. }\end{array}$ & $\mathrm{P}$ \\
\hline & & $\begin{array}{l}\text { On Sunday, we will bake a small tree with } \\
\text { Alex. }\end{array}$ & LP \\
\hline & city & You can reach the city in little time. & $\mathrm{P}$ \\
\hline
\end{tabular}




\begin{tabular}{|c|c|c|c|}
\hline \multirow{7}{*}{$\begin{array}{l}\text { Syntactic } \\
\text { violations }\end{array}$} & & You can arrive the city in little time. & LP \\
\hline & \multirow{2}{*}{ books } & John loaded the table with books. & $P$ \\
\hline & & John put the table with books. & LP \\
\hline & \multirow{2}{*}{ icing } & Helen covered the cake with icing. & $P$ \\
\hline & & Helen spread the cake with icing. & LP \\
\hline & \multirow{2}{*}{ cushions } & $\begin{array}{l}\text { She got ready to sew some cushions for her } \\
\text { new home. }\end{array}$ & $P$ \\
\hline & & $\begin{array}{l}\text { She got ready to sleep some cushions for the } \\
\text { new home. }\end{array}$ & LP \\
\hline \multirow{5}{*}{ Common } & \multirow{2}{*}{ groom } & $\begin{array}{l}\text { I don't like this picture. The bride and groom } \\
\text { both look tired. }\end{array}$ & $\mathrm{P}$ \\
\hline & & $\begin{array}{l}\text { I don't like this painting. The horse and } \\
\text { groom both look tired. }\end{array}$ & LP \\
\hline & \multirow{2}{*}{ chips } & $\begin{array}{l}\text { It's a great place. I love the fish and chips } \\
\text { served in this pub. }\end{array}$ & $P$ \\
\hline & & $\begin{array}{l}\text { It's a great place. I love the bread and chips } \\
\text { served in this pub. }\end{array}$ & LP \\
\hline & pepper & $\begin{array}{l}\text { That's unbelievable. I forgot the salt and } \\
\text { pepper for our breakfast. }\end{array}$ & $\mathrm{P}$ \\
\hline
\end{tabular}




\begin{tabular}{|l|l|l|l|}
\hline \multirow{2}{*}{ dogs } & $\begin{array}{l}\text { That's embarrassing. I forgot the juice and } \\
\text { pepper for our breakfast. }\end{array}$ & LP \\
\hline \multirow{2}{*}{} & $\begin{array}{l}\text { It's common sense. Cats and dogs should } \\
\text { not be kept indoors for too long. }\end{array}$ & P \\
\cline { 2 - 3 } & It's common sense. Birds and dogs should & LP \\
\hline
\end{tabular}

\subsection{Procedure}

Before starting the experiment, participants gave informed consent to take part. They were then allocated to the next available laptop. On the laptop, they filled out a short questionnaire which asked for their age, gender (male, female or non-binary), whether they were a native or non-native speaker, had a history of neurological illness or had a hearing impairment. They then saw instructions of the task displayed on the laptop screen (Figure 2) and started the experiment. Stimulus lists alternated on each machine and researchers did not know which would run next. Items in each list were presented in randomized order. Participants listened to the stimuli using noise-cancelling headphones and responded to the target by pushing the space bar on the laptop keyboard. There were no practice trials. Filling out the questionnaire, reading the instructions and carrying out the task took about three minutes for most participants.

After the experiment, participants saw their mean RT (in ms) displayed on the laptop screen. They picked up their button and one of the researchers offered to write their mean RT on it with a permanent marker. Real-time results were displayed on a separate computer screen, 
visible to all visitors (see Figure 1). The screen presentation cycled through three graphs with the following headings. The first was "How sensitive are we to unexpected words?" and displayed a bar chart showing average RT difference for predictable versus less predictable targets in each condition. The second had the heading "Does age matter?", and displayed a scatterplot of average RT difference between unpredicted and predicted targets by age, with a correlation line. The third screen was titled "Are native or non-native speakers of English more sensitive to unexpected English words?" and displayed a bar chart showing average RT difference across all conditions for native versus non-native speakers of English.

\section{Figure 2}

WMT instruction screen.

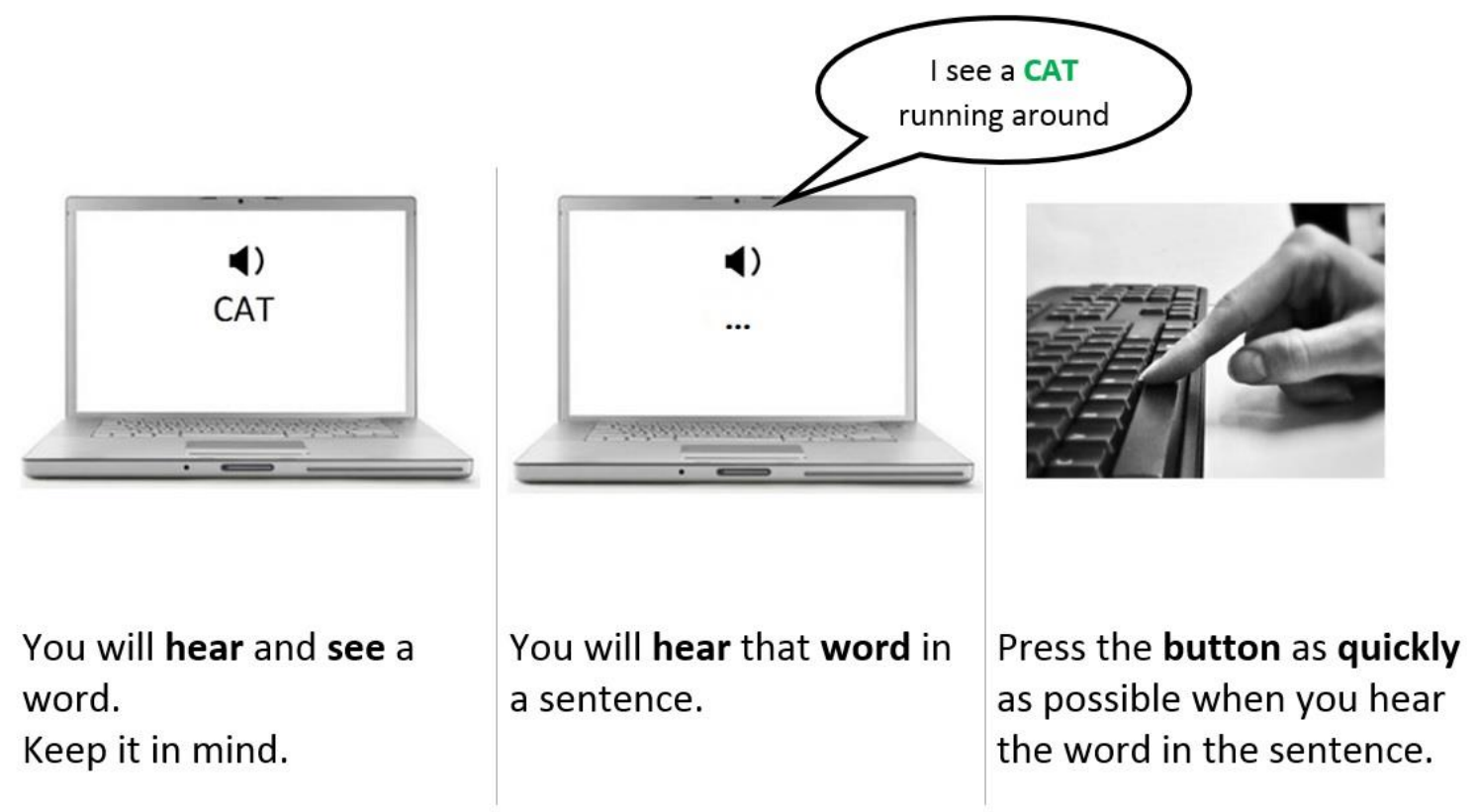

Press SPACEBAR to start the experiment. 


\section{Results}

\subsection{WMT}

\subsubsection{Analysis methods}

We applied generalised linear mixed effects models (Baayen, Davidson, \& Bates, 2008), using Ime4 (Bates, Mächler, Bolker, \& Walker, 2015) and knitr packages (Xie, 2018) for the R environment (R Core Team, 2019). Graphical representations were created using ggpirate (Braginsky, 2018). Reliability was calculated using the psych package (Revelle, 2021).

The experimental factors were age (a continuous variable), native language (native/nonnative English speaker), predictability (high/low predictability for the target condition), and manipulation type (semantic/syntactic/collocations in the language manipulation condition). We included all experimentally manipulated variables and their interactions as fixed factors in the models, regardless of whether their contribution was significant. Participant was included as a random effect with as full a random slope structure as would converge (in this case only the interaction of native language by predictability, without the manipulation type or age) as recommended by Barr, Levy, Scheepers, \& Tily (2013). Item was included as a random effect with random intercepts only. Additionally, we included list into the model as a fixed factor for the randomised stimuli list which was part of the experimental manipulation. However, list was considered a control factor not relevant to our hypotheses. We, therefore, included it as a main effect, but did not interpret it. Predicting variables were centred to reduce collinearity effects between main effects and interactions, so that the intercept corresponded to the grand-mean (in log odds space) and main effects were evaluated as average effects over all levels rather than having a baseline level for each variable. For manipulation type, which has more than two levels which are not naturally 
ordered, we used a centred contrasts coding instead. To assess whether performance was above chance, data were compared to the intercept. All reported models converged using the Bound Optimization by Quadratic Approximation (BOBYQA optimization; Powell, 2009). Since all models had a continuous outcome variable (RTs, standardized RTs or RT differences) we calculated $p$-values using the ImerTest package (Kuznetsova, Brockhoff, \& Christensen, 2017) and Satterthwaite approximation for degrees of freedom.

The full model included the age by native language by predictability by manipulation type interaction and any lower level interactions within that. Since manipulation type has three levels, and our method of centring only shows two levels at once, we ran the same model with a different manipulation type as the baseline to get to the third level. Gender was not added into the final model, as it did not significantly improve the model fit. The final model structure is as follows:

$R T \sim$ age * native language * predictability * manipulation type + list + (native language : predictability / participant) + (1 / item) .

\subsubsection{Effects}

Although we ran models including all of the experimentally manipulated variables and their interactions, we only report statistics for the key effects relevant to our hypotheses. The 
dataset, code and analyses are available here:

https://osf.io/jy4zr/?view_only=3312962cdabe4f348f7d46f8b4d9c523

Table 2

Model results for the analyses of effects of age, native language, predictability, and manipulation type on RT on a WMT. 


\begin{tabular}{|c|c|c|c|c|}
\hline Effect & $\boldsymbol{\beta}$ & SE & $\mathbf{t}$ & $\mathbf{p}$ \\
\hline Age & 1.639 & 0.357 & 4.591 & $<.001$ \\
\hline Native language & 34.528 & 13.169 & 2.622 & .010 \\
\hline Predictability & 42.547 & 20.010 & 2.126 & .048 \\
\hline $\begin{array}{l}\text { Age by } \\
\text { predictability }\end{array}$ & -0.410 & 0.444 & -0.923 & .358 \\
\hline $\begin{array}{l}\text { Native language } \\
\text { by predictability }\end{array}$ & -28.906 & 16.751 & -1.726 & .089 \\
\hline \multicolumn{5}{|c|}{ Predictability by manipulation type } \\
\hline $\begin{array}{l}\text { Collocations vs } \\
\text { semantic }\end{array}$ & 2.297 & 48.497 & 0.047 & .963 \\
\hline $\begin{array}{l}\text { Collocations vs } \\
\text { syntactic }\end{array}$ & -24.038 & 48.593 & -0.495 & .627 \\
\hline $\begin{array}{l}\text { Semantic vs } \\
\text { syntactic }\end{array}$ & -26.335 & 48.583 & -0.542 & .595 \\
\hline \multicolumn{5}{|c|}{ Age by predictability by manipulation type } \\
\hline $\begin{array}{l}\text { Collocations vs } \\
\text { semantic }\end{array}$ & 0.507 & 0.987 & 0.513 & .608 \\
\hline $\begin{array}{l}\text { Collocations vs } \\
\text { syntactic }\end{array}$ & -0.738 & 1.005 & -0.734 & .463 \\
\hline
\end{tabular}




\begin{tabular}{|l|l|l|l|l|}
\hline Semantic vs & -1.244 & 1.008 & -1.235 & .217 \\
\hline syntactic & \multicolumn{3}{|l|}{} \\
\hline Native language by predictability by manipulation type & & .895 \\
\hline Collocations vs & -4.842 & 36.606 & -0.132 & \\
\hline Semantic & -69.688 & 37.044 & -1.881 & .060 \\
\hline syntactic & & & -1.761 & .079 \\
\hline Semantic vs & -64.845 & 36.830 & & \\
\hline syntactic & & & & \\
\hline
\end{tabular}

There was a significant relationship between RT and age, in that older participants were slower. Also, native speakers were overall significantly faster to respond to the stimuli $(M=$ $229 \mathrm{~ms}, \mathrm{SD}=128 \mathrm{~ms})$ than non-native speakers $(\mathrm{M}=239 \mathrm{~ms}, \mathrm{SD}=124 \mathrm{~ms})$. There was a significant main effect of the type of word monitoring manipulation, as participants responded more slowly in the low predictability condition ( $\mathrm{M}=253 \mathrm{~ms}, \mathrm{SE}=118 \mathrm{~ms})$ than the high predictability condition ( $\mathrm{M}=212 \mathrm{~ms}, \mathrm{SD}=132 \mathrm{~ms})$.

There was no significant interaction of WMT manipulation by trial type; WMT effects were not significantly different in the syntactic (high predictability $M=229 \mathrm{~ms}, \mathrm{SD}=131 \mathrm{~ms}$; low predictability $\mathrm{M}=252 \mathrm{~ms}, \mathrm{SD}=126 \mathrm{~ms}$ ), semantic (high predictability $\mathrm{M}=231 \mathrm{~ms}, \mathrm{SD}=118$ ms; low predictability $\mathrm{M}=275 \mathrm{~ms}, \mathrm{SD}=116 \mathrm{~ms}$ ) and collocation conditions (high predictability $M=177 \mathrm{~ms}, \mathrm{SD}=139 \mathrm{~ms}$; low predictability $\mathrm{M}=231 \mathrm{~ms}, \mathrm{SD}=108 \mathrm{~ms}$ ). There was no significant interaction of WMT manipulation with age, so older participants did not significantly differ from younger participants in their responses to predictability 
manipulations. There was no significant interaction between the WMT manipulation type and native language, meaning that WMT manipulations did not elicit significantly different responses between native (high predictability $M=206$ ms, SD = 133 ms; low predictability $M$ $=252 \mathrm{~ms}, \mathrm{SD}=119 \mathrm{~ms}$ ) and non-native (high predictability $\mathrm{M}=223 \mathrm{~ms}, \mathrm{SD}=130 \mathrm{~ms}$; low predictability $\mathrm{M}=254 \mathrm{~ms}, \mathrm{SD}=116 \mathrm{~ms}$ ) speakers of English. There was no significant interaction between age, WMT manipulation type, and trial type, meaning that older participants did not show significantly different types of reactions to WMT manipulations across the manipulation categories.

Finally, there was no significant interaction between WMT manipulation type, native language and trial type, suggesting non-native participants and native participants did not show different types of reactions to WMT manipulations across the manipulation categories, as seen in Figure 3. Note, however that the effect for the latter two interactions are close to the significance threshold, suggesting that non-native speakers may be less sensitive to syntactic manipulations.

We measured the reliability of our stimuli responses using Cronbach's Alpha. The value was $\alpha=.71$, indicating acceptable consistency of RTs. 
Figure 3

RTs for native and non-native participants, comparing predictable versus less predictable contexts in stimuli that were manipulated semantically, syntactically, or by the strength of word collocations. The horizontal line in each violin indicates the mean performance with the band around it showing $95 \% \mathrm{Cl}$.

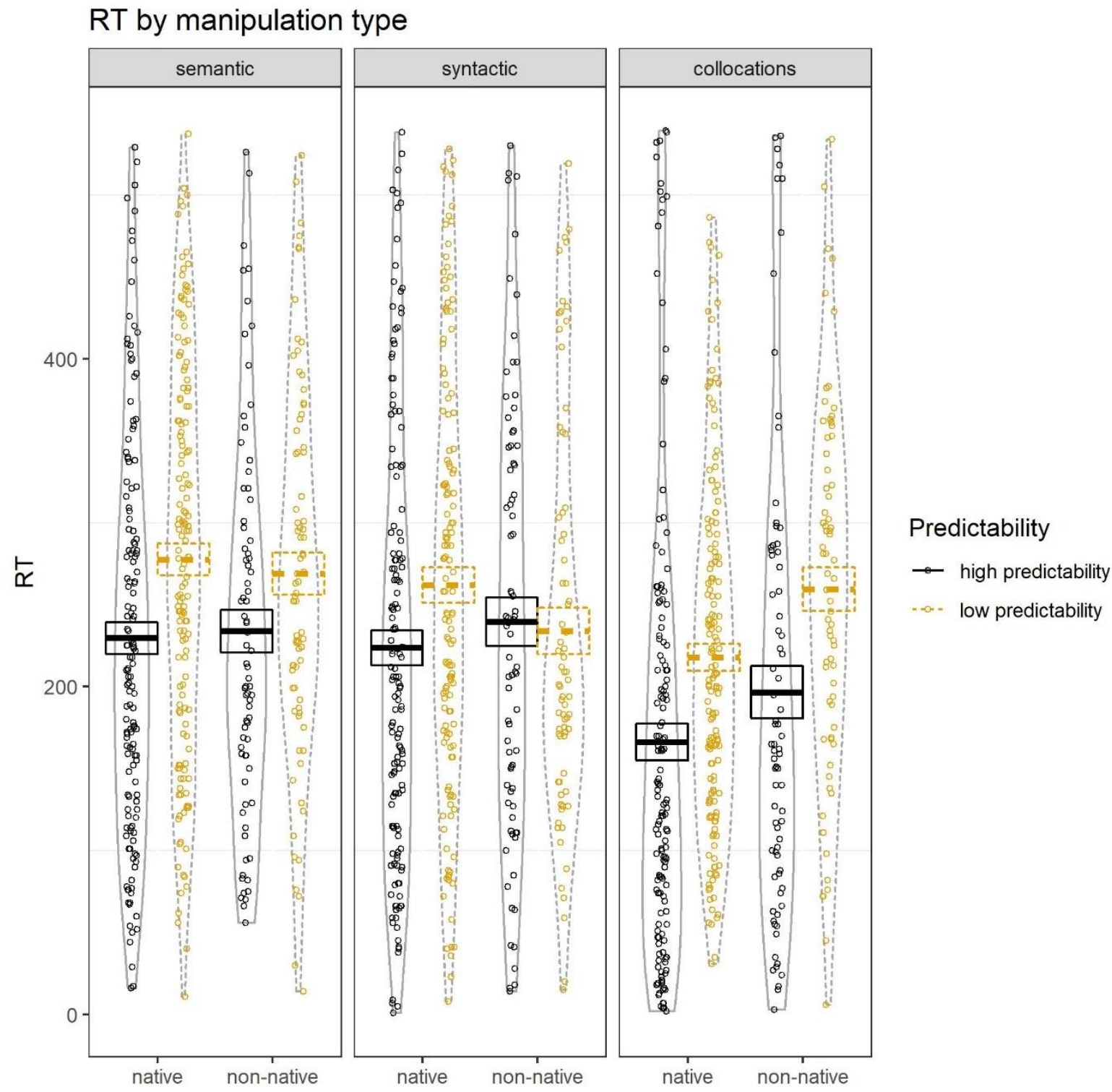




\subsection{Engagement}

We did not systematically collect any data on visitor satisfaction, so this section contains our observations and impressions. Overall, visitors appeared to enjoy the installation. Participants were keen to take part in the experiment, and from after about two hours, when more visitors appeared, until the end of the festival, the installation was crowded at all times. Most participants sought a conversation with the researchers, especially after the experiment, and having taken part in the study made it easier to communicate ideas about a predictive language system. The screen displaying WMT results helped explain the design of the experiment. Displaying individuals' average RT at the end of the experiment, and offering to write it on the badges, led to a fun sense of competition within participant groups as many visitors who arrived together enjoyed comparing their performances: e.g. one group decided that the participant with the slowest response would buy drinks. From our observation, engagement with the Power Point presentation (Figure 1, S2) was small in comparison with the engagement with the tasks and the experimenters.

\section{Discussion}

We carried out a public experiment during a local festival as a mean of public engagement, and of collecting data to investigate different levels of language processing. In order to make the test attractive as part of a public event, and to test a large number of people, we made a number of methodological innovations to the WMT paradigm which reduced the duration of each test session to about three minutes. In a WMT, the main effect is that of sentence frame, i.e. whether a target word, in a given context, is more or less predictable. 
We tested words in predictable and less predictable grammatical contexts, semantic frames, and word collocations (e.g. salt and pepper vs. juice and pepper). Since we introduced substantial methodological changes, the discussion of results serves as a test of validity. Results which are either replications of previous studies, or which would be predicted by psycholinguistic theory, would suggest that the experiment measured real language processes.

We found that context had a significant effect on participants' RTs as they were slower when the word was less predictable in its frame. This serves as a replication of typical WMTs, suggesting that the adapted methods have validity. Reliability for the measure was promising for such a short adaptation of typical WMTs. To our knowledge, the effects of grammatical, semantic and collocational manipulations have not been compared in a WMT study. Nevertheless, we expected different manipulations of linguistic information to elicit different effect sizes, as they are assumed to be processed by different neurological networks. We were therefore surprised to see that differences in sensitivity across the three conditions were so small and not significant. One exception, however, was the interaction between manipulation condition and native language (see below).

Older people were overall slower but showed the same sensitivity to context, which is consistent with previous findings. Previous WMT studies on aging found no effect on processing grammatical and semantic context (Tyler et al., 2010; Waldstein \& Baum, 1992). Reviews of language in aging (Burke \& Shafto, 2008; James \& Goring, 2018) find that age effects on language are strongest in production. In language reception or comprehension, findings differ depending on the nature of the task, with age effects being stronger when the task is off-line and explicit, for example in experiments involving recall or judgment. One 
explanation may be that recall and judgment tasks pose higher demands to working memory and the ability to learn and perform a complex new task, and that both are affected by aging (Burke \& Magkay, 1997; Thornton \& Light, 2006).

The main effect of native language was not significant, as sensitivity to context was similar in L1 and L2 speakers across all items. This is unexpected, since previous WMT studies found differences between participants of these two populations. Kilborn (1992) found that sensitivity to grammatical context in L2 English speakers was comparable to sensitivity of L1 speakers under noise conditions. Granena (2013) also found differences between L1 and L2 Spanish speakers in a grammatical WMT. However, differences were only significant in a group of "late" learners, i.e. speakers who started learning English after age 16 and who had spent, on average, 8.4 years in Spain. Early learners, on the other hand, were not significantly different from native speakers. Similarly, Suzuki (2017) found that L2 learners of Japanese were more sensitive to grammatical violations in a WMT the longer they had lived in Japan. While we were not able to collect data on our L2 speakers' proficiency or experience, it is possible that the weaker and non-significant main effect we found was due to our group containing more advanced speakers of English. Future research in this area should aim to include measures of participant background to explore potential differences due to variation in e.g. proficiency, age at which they started learning, or socio-economic background, to be able to tease apart the reasons behind differences in learner effects.

Despite this, we found suggestions of a possible interaction between native language and type of linguistic manipulation. When comparing the effect of grammatical, semantic, and collocational manipulation, we found no main effect, and no interaction with age. However, the interaction effect between manipulation and native language (Figure 3) was close to 
significance thresholds. In L2 but not L1 speakers, sensitivity to grammatical information (verb argument structure) numerically appeared weaker than sensitivity to lexical-semantic or collocational information. While we need to restrain from generalizing from our sample, we note that the effect is in line with data from other experiments. It also seems in line with theories of second language acquisition which propose that L2 speakers are often engaged in "shallow" grammatical processing of language, with language networks paying more attention to semantic coherence than grammatical structure (Clahsen \& Felse, 2006; Guo, Guo, Yan, Jiang, \& Peng, 2009; Yudes, Maclzo, Morales, \& Bajo, 2013; Zheng \& Lemhöfer, 2019). The idea of shallow processing extends to common collocations such as fish and chips: these are considered formulaic language, and thought to be stored holistically as a single language unit, while other combinations (e.g. bread and chips) rely more on processing of each individual word and its grammatical combination (Conklin \& Schmitt, 2012). Future research should be conducted for replication in order to further qualify the potential difference in sensitivity to collocations between L1 and L2 speakers. .

Importantly, we regard this study as proof-of-concept, and while effects are in line with the literature, a confirmatory study investigating our variables requires more participants (Brysbaert, 2019). Another limitation concerns study design, since the lexical frequency of target words was not considered, which impacts the comparability of manipulation conditions. We also note that our stimulus set was rather small. A follow-up study could take lexical frequency into account in the stimuli creation, and could include more sentence stimuli to avoid extending the duration of the experiment, by creating a larger set from which only a subset is selected for the individual participant. This would also likely be beneficial for the reliability of the measure. Note that a follow-up study with more sentence 
stimuli would require an increase in participant numbers in order to ensure enough observations per item.

In a public event it is not possible to control for how much the participant knows about the task. Knowledge about the experimental design, which we discussed with participants after they completed the task, can result in more explicit processing of language as participants direct their attention to the manipulation. It is possible that knowledge about the design "leaked" to individuals who later took part in the experiment. Finally, a public event is noisy and full of distractions, and despite testing taking place behind room dividers and with noise-cancelling headphones, it was not possible to create optimally quiet test conditions.

Other limitations concern the participant sample. We note that every recruitment strategy introduces selection biases to the sample. In the case of recruiting visitors from a sciencethemed festival one would expect participants with higher levels of education and perhaps more proficient English skills. In the case of older participants, one would expect them to have a more active lifestyle. Therefore, while we did not limit ourselves to recruiting from a student subject pool and our recruitment addresses issues with participant group homogeneity to some degree, our sample may not be representative enough to accurately represent age effects and effects of speaking English as a second language.

In summary, we demonstrate that our version of a word monitoring task, which introduces substantial methodological changes, produces data that are compatible with other studies and views about language processing. The methods meet Hartshorne et al.'s (2018) description for a test that could be popular, as participants were entertained, motivated, and completed it quickly. We see the usefulness of the task in environments which allow testing large numbers of participants who either do not have much time, or have difficulties 
being engaged in a longer task. These can be public events, but also school environments and remote online testing. 
References

Baayen, R. H., Davidson, D. J., \& Bates, D. M. (2008). Mixed-effects modeling with crossed random effects for subjects and items. Journal of Memory and Language, 59(4), 390412. https://doi.org/10.1016/j.jml.2007.12.005

Barr, D. J., Levy, R., Scheepers, C., \& Tily, H. J. (2013). Random effects structure for confirmatory hypothesis testing: Keep it maximal. Journal of Memory and Language, 68(3), 255-278. https://doi.org/10.1016/j.jml.2012.11.001

Bates, D., Mächler, M., Bolker, B., \& Walker, S. (2015). Fitting Linear Mixed-Effects Models Using Ime4. Journal of Statistical Software, 67(1), 1-48. https://doi.org/10.18637/jss.v067.i01

Baum, S. R. (1989). On-line sensitivity to local and long-distance syntactic dependencies in Broca's aphasia. Brain and Language, 37(2), 327-338. https://doi.org/10.1016/0093$934 \times(89) 90021-7$

Baum, S. R. (1991). Sensitivity to Syntactic Violations Across the Age-Span: Evidence from a Word-Monitoring Task. Clinical Linguistics \& Phonetics, 5(4), 317-328. https://doi.org/10.3109/02699209108985899

Bloomsbury Festival. 19-23 October 2016. (2016). London: Bedford House Community Centre.

Braginsky, M. (2018). ggpirate: pirate plots for ggplot2.

Brekelmans, G., \& Meitanis, V. (2016). Phonetics for Word Monitoring manual.

Brysbaert, M. (2019). How Many Participants Do We Have to Include in Properly Powered 
Experiments? A Tutorial of Power Analysis with Reference Tables. Journal of Cognition, 2(1), 16. https://doi.org/10.5334/joc.72

Burke, D.M., \& Shafto, M. A. (2008). Language and Aging. In F. I. M. Craik \& T. A. Salthouse (Eds.), The Handbook of Aging and Cognition (pp. 373-443). New York: Psychology Press.

Burke, Deborah M., \& Magkay, D. G. (1997). Memory, language, and ageing. Philosophical Transactions of the Royal Society B: Biological Sciences. https://doi.org/10.1098/rstb.1997.0170

Clahsen, H., \& Felse, C. (2006, January). Continuity and shallow structures in language processing. Applied Psycholinguistics, Vol. 27, pp. 107-126. https://doi.org/10.1017/S0142716406060206

Clark, A. (2013). Whatever next? Predictive brains, situated agents, and the future of cognitive science. Behavioral and Brain Sciences, 36(3), 181-204. https://doi.org/10.1017/S0140525X12000477

Conklin, K., \& Schmitt, N. (2012). The Processing of Formulaic Language. Annual Review of Applied Linguistics, 32, 45-61. https://doi.org/10.1017/S0267190512000074

Ellis, N. C. (2008). Implicit and explicit knowledge about langauge. In Encyclopedia of Language and Education (pp. 119-131). Berlin: Springer.

Ferreira, F., \& Chantavarin, S. (2018). Integration and Prediction in Language Processing: A Synthesis of Old and New. Current Directions in Psychological Science, 27(6), 443-448. https://doi.org/10.1177/0963721418794491

Granena, G. (2013). Individual Differences in Sequence Learning Ability and Second 
Language Acquisition in Early Childhood and Adulthood. Language Learning. https://doi.org/10.1111/lang.12018

Guo, J., Guo, T., Yan, Y., Jiang, N., \& Peng, D. (2009). ERP evidence for different strategies employed by native speakers and L2 learners in sentence processing. Journal of Neurolinguistics, 22(2), 123-134. https://doi.org/10.1016/j.jneuroling.2008.09.001

Haarmann, H. J., \& Kolk, H. H. J. (1994). On-line Sensitivity to Subject-Verb Agreement Violations in Broca's Aphasics: The Role of Syntactic Complexity and Time. Brain and Language, 46(4), 493-516. Retrieved from http://www.sciencedirect.com/science/article/pii/S0093934X84710285

Hartshorne, J. K., Tenenbaum, J. B., \& Pinker, S. (2018). A critical period for second language acquisition: Evidence from 2/3 million English speakers. Cognition. https://doi.org/10.1016/j.cognition.2018.04.007

James, L. E., \& Goring, S. A. (2018). Language and Cognitive Aging. In Oxford Research Encyclopedia of Psychology. https://doi.org/10.1093/acrefore/9780190236557.013.375

Kidd, E., Donnelly, S., \& Christiansen, M. H. (2018). Individual Differences in Language Acquisition and Processing. Trends in Cognitive Sciences, 22(2), 154-169. https://doi.org/10.1016/J.TICS.2017.11.006

Kilborn, K. (1992). On-line Integration of Grammatical Information in a Second Language. Advances in Psychology. https://doi.org/10.1016/S0166-4115(08)61504-6

Kilborn, K., \& Moss, H. (1996). Word Monitoring. Language and Cognitive Processes, 11(6), 689-694. https://doi.org/10.1080/016909696387105

Kuperberg, G. R., McGuire, P. K., \& David, A. S. (1998). Reduced sensitivity to linguistic 
context in schizophrenic thought disorder: Evidence from on-line monitoring for words in linguistically anomalous sentences. Journal of Abnormal Psychology. https://doi.org/10.1037/0021-843X.107.3.423

Kutas, M., van Petten, C., \& Kluender, R. (2006). Psycholinguistics electrified II: 1994-2005. In M. J. Traxler \& M. A. Gernsbacher (Eds.), Handbook of Psycholinguistics (2nd ed., pp. 659-724). New York, NY: Elsevier.

Kuznetsova, A., Brockhoff, P. B., \& Christensen, R. H. B. (2017). ImerTest Package: Tests in Linear Mixed Effects Models . Journal of Statistical Software, 82(13). https://doi.org/10.18637/jss.v082.i13

Marinis, T. (2010). Using on-line processing methods in language acquisition research. In E. Blom \& S. Unsworth (Eds.), Experimental methods in language acquisition research (pp. 139-162). Amsterdam: John Benjamins.

Marslen-Wilson, W. D., \& Tyler, L. K. (1975). Processing structure of sentence perception. Nature, 257, 784-786.

Marslen-Wilson, W., \& Tyler, L. K. (1980). The temporal structure of spoken language understanding. Cognition, 8(1), 1-71. https://doi.org/10.1016/0010-0277(80)90015-3

Montgomery, J. W., \& Leonard, L. (2006). Effects of acoustic manipulation on the real-time inflectional processing of children with specific language impairment. Journal of Speech, Language, and Hearing Research, 49(6), 1238-1256. https://doi.org/https://doi.org/10.1044/1092-4388(2006/089)

Powell, M. (2009). The BOBYQA algorithm for bound constrained optimization without derivatives. NA Report NA2009/06, 39. https://doi.org/10.1.1.443.7693 
Revelle, W. (2021). psych: Procedures for Psychological, Psychometric, and Personality Research. Northwestern University, Evanston, Illinois. R package version 2.1.6, https://CRAN.R-project.org/package=psych.

R Core Team. (2019). R: A Language and Environment for Statistical Computing. Vienna, Austria: R Foundation for Statistical Computing.

Shanks, D. (2005). Implicit learning. In K. Lamberts \& R. L. Goldstone (Eds.), Handbook of Cognition (pp. 202-220). London: Sage.

Shaoul, C., Baayen, R. H., \& Westbury, C. F. (2014). N-gram probability effects in a cloze task. The Mental Lexicon, 9(3), 437-472. https://doi.org/https://doi.org/10.1075/ml.9.3.04sha

Siyanova-Chanturia, A., Conklin, K., Caffarra, S., Kaan, E., \& van Heuven, W. J. B. (2017). Representation and processing of multi-word expressions in the brain. Brain and Language, 175, 111-122. https://doi.org/10.1016/j.bandl.2017.10.004

Street, J. A., \& Dąbrowska, E. (2010). More individual differences in language attainment: How much do adult native speakers of English know about passives and quantifiers? Lingua, 120(8), 2080-2094. Retrieved from http://www.sciencedirect.com/science/article/pii/S0024384110000185

Street, J. A., \& Dąbrowska, E. (2014). Lexically specific knowledge and individual difference in adult native speakers' processing of the English passive. Applied Psycholinguistics, 35(1), 97-118.

Suzuki, Y. (2017). Validity of new measures of implicit knowledge: Distinguishing implicit knowledge from automatized explicit knowledge. Applied Psycholinguistics, 38(5), 
1229-1261. https://doi.org/10.1017/S014271641700011X

Suzuki, Y., \& DeKeyser, R. (2015). Comparing Elicited Imitation and Word Monitoring as Measures of Implicit Knowledge. Language Learning, 65(4), 860-895. https://doi.org/10.1111/LANG.12138

Thornton, R., \& Light, L. L. (2006). Language Comprehension and Production in Normal Aging. In Handbook of the Psychology of Aging. https://doi.org/10.1016/B978012101264-9/50015-X

Tyler, L. K., Shafto, M. A., Randall, B., Wright, P., Marslen-Wilson, W. D., \& Stamatakis, E. A. (2010). Preserving syntactic processing across the adult life span: The modulation of the frontotemporal language system in the context of age-related atrophy. Cerebral Cortex. https://doi.org/10.1093/cercor/bhp105

Waldstein, R. S., \& Baum, S. R. (1992). The influence of syntactic and semantic context on word-monitoring latencies in normal aging. Journal of Speech Language Pathology and Audiology, 16(3), 217-222.

Xie, Y. (2018). knitr: A General-Purpose Package for Dynamic Report Generation in R.

Yudes, C., Maclzo, P., Morales, L., \& Bajo, M. T. (2013). Comprehension and error monitoring in simultaneous interpreters. Applied Psycholinguistics, 34(5), 1039-1057. https://doi.org/10.1017/S0142716412000112

Zheng, X., \& Lemhöfer, K. (2019). The "semantic P600" in second language processing: When syntax conflicts with semantics. Neuropsychologia, 127, 131-147. https://doi.org/10.1016/j.neuropsychologia.2019.02.010 


\section{Appendix A. Cloze task}

\section{Methods}

The cloze task is a sentence completion task. Incomplete sentences were displayed on one side of a poster board (see Figure 1). We provided post-it notes for visitors to write down their answers. Visitors could put each post-it note on the back of the poster board, where each sentence was displayed again. In this way, visitors could look at all previous answers and see where there was agreement or disagreement. There were three incomplete sentences with varying degrees of contextual constraint:

(a) When you go to bed, turn off the ...

(b) I didn't find the key to open the ...

(c) He was surprised to find that the large box was filled with ...

The task was unsupervised. There were no time constraints, and visitors were able to complete it in groups if they wanted.

\section{Results}

Table A1 summarizes the cloze probabilities collected throughout the day of the event. It should be noted that we did not collect demographic data of people participating in this task. The more contextually constrained sentences (a) and (b) frequently elicited the predictable targets (light(s); door, see Table 2). Some participants, however, answered with more creative variations such as "When you go to bed, turn off the brain (5) / problems (1)" or "I didn't find the key to open the heart (3) / universe (1)". As expected, sentence (c), which had the weakest constraint context, elicited the greatest variety of answers, with a maximum cloze probability of .06 for "nothing" and "toys" (Table A1).

Table A1. Most common answers in the cloze task.

\begin{tabular}{|c|c|c|l|}
\hline & $\begin{array}{l}\text { When you go to } \\
\text { bed, turn off the ... }\end{array}$ & $\begin{array}{l}\text { I didn't find the key } \\
\text { to open the ... }\end{array}$ & $\begin{array}{l}\text { He was surprised to find } \\
\text { that the large box was } \\
\text { filled with ... }\end{array}$ \\
\hline $\mathrm{N}$ & 87 & 88 & 72 \\
\hline & light(s) (.47) & door (.36) & nothing (.06) \\
\hline
\end{tabular}




\begin{tabular}{|c|c|c|}
\hline $\begin{array}{c}\text { Most common } \\
\text { answer }\end{array}$ & & toys (.06) \\
(cloze & & \\
probability) & & \\
\hline
\end{tabular}

